\title{
Essential thrombocythemia - a predisponent factor for stroke
}

\section{SUMMARY}

The essential thrombocythemia is one of the seven described forms of myeloproliferative neoplasms. It is characterized by megakaryocytic hyperplasia with consequent thrombocytosis maintained in the peripheral blood, favoring the occurrence of thrombo-hemorrhagic phenomena. We present the case of an 81-year-old woman with a history of ischemic stroke in the context of a sustained thrombocytosis, which led to a spinal study and a search for the V617F mutation in the JAK2 gene, which was positive. The patient started cytoreductive therapy with hydroxyurea with favorable current evolution.

KEYWORDS: Thrombocytosis. Stroke. Blood Coagulation Disorders.

\section{INTRODUCTION}

Essential thrombocythemia (ET), characterized by a thrombocytosis maintained at $450 \times 10^{9} / \mathrm{L}$ or more, together with polycythemia vera constitute primary myelofibrosis, chronic myeloid leukemia, chronic neutrophil leukemia, systemic mastocytosis, and non-classifiable myeloproliferative neoplasm, a group of hyper spreadable entities with several clinical-laboratorial resemblances - the myeloproliferative neoplasms (MNP) ${ }^{1,2}$

The form of the ET is quite variable. Most patients present symptoms related to the thrombosis of thick or large blood vessels or minor hemorrhaging. The thrombotic incidents at the time of diagnosis and during the follow-up of the disease occur in rates of $10-29 \%$ and $8-31 \%$, respectively. ${ }^{2}$
With regard to the ET, three important mutations are described: one of the tyrosine-kinase cytoplasmic genes, the JAK2 V617F, present in around 50-60\% of the cases; one of the protein genes linked to the endoplasmic reticulum, CALR, which occurs in $25-30 \%$ of the cases; and the receiver gene of thrombopoietin, MPL W515, present in 3-5\%. ${ }^{3}$ The discovery of these mutations is considered a key tool for the diagnosis of MNP, including ET. Although not always present, it is reasonable to consider analysing them when evaluating patients with thrombocytosis in another unexplained form. A positive test indicates an underlying MNP, being, therefore, necessary a medullar biopsy as well as a cytogenetic analysis to differentiate the MNP. ${ }^{2}$ 
Most essential thrombocytosis patients are asymptomatic or suffer from unthreatening microvascular malfunction and are successfully treated with a low dose of aspirin. On the other hand, the use of cytoreducing medical therapy to diminish the risk of thrombosis in ET is adequate, provided this is applied to patients with a high thrombotic risk. ${ }^{4}$

\section{CASE REPORT}

We present the case of an 81-year-old female patient with personal data of atrial fibrillation, high blood pressure, dementia syndrome, and two prior hospital admissions (in two consecutive months) due to transient ischaemic attack (TIA). The condition was initially controlled with hypnosis using Warfarin, but large variations were registered in the rate of the international normalized ratio (INR); therefore, the hypnosis was changed to Rivaroxaban. The patient was once more admitted a month after the last TIA because of a sudden muscle reduction in the strength of the upper- and lower-right limbs and dysarthria. When admitted, the CT scanning of the head presented frontal, temporal and left parieto-occipital hypodensity revealing recent strokes. Upon admission, she maintained hemodynamic and clinical stability, confirming the already-known arrhythmia. The echo-doppler exam of the neck vessels showed a homogenous atheroma with parietal thickness and a moderate calcification in the bifurcations, without evidence of stenosis/signs of hemodynamic repercussion. The echocardiogram documented a slight mitral insufficiency and a slight to moderate tricuspid regurgitation with widened atria. The analytics showed thrombocytosis of $615 \times 10^{9} / \mathrm{L}$. On the fifth day of hospitalization, there was a neurological aggravation with right hemiplegia, overall aphasia, and right homonymous hemianopsia. A new CT scanning of the head was made, which showed a recent ischemic injury in a deep and cortical area of the middle cerebral artery, without signs of hemorrhagic trans- formation. The new analytical control confirmed the presence of thrombocytosis of $810 \times 10^{9} / \mathrm{L}$. Considering the hypothesis of a recurrent ischemic cerebral vascular accident (CVA) in a thrombocytosis context, a spinal study was made and a survey on the $\mathrm{V} 617 \mathrm{~F}$ mutation in the JAK2 gene, which was positive, thus confirming the diagnosis of essential thrombocythaemia. Besides the hypocoagulation (changed to apixaban), a cytoreducing therapy was started with hydroxyurea. A follow-up procedure was maintained in hospital appointments registering a favorable neurological and hematologic evolution.

\section{DISCUSSION}

Although essential thrombocythaemia is a less frequent cause for a stroke, before the specter of thrombocytosis, it is a diagnostic that must be considered since it requires a high degree of caution and a directed investigation. For instance, it should be noted that in a study made in Lyon covering 763 patients with MNP, most cerebrovascular episodes occurred with essential thrombocythaemia. ${ }^{5}$ In another study, in a series of 148 patients with an average follow-up of six years, it was possible to see that cerebral ischemia was the most common ischemic manifestation in ET cases, both in the diagnosis stage and the follow-up. ${ }^{6}$

The present study allowed to establish essential thrombocythaemia as the cause for several vascular occurrences, despite the atherosclerotic and cardioembolic risk factors presented by the patient. One must also bear in mind the main risk factors for thrombotic/ischemic events in patients with ET, including age $(\geq 60)$ and previous vascular events, as it happened in the described case. ${ }^{7,8}$

The decrease of the platelet count to normal ( $<400 x 109 / \mathrm{L})$ in symptomatic patients with ET using a cytoreducing therapy is clearly associated with a significant reduction in the occurrence of arterial and venous thrombotic events. ${ }^{9}$

PALAVRAS-CHAVE: Trombocitose. Acidente Vascular Cerebral. Transtornos da Coagulação Sanguínea.

\section{REFERENCES}

1 Goldman L, Schafer Al. Goldman-Cecil Medicine. $25^{\text {th }}$ ed. vol. 2. Rio de Janeiro: Elsevier; 2015.

2 Hoffman R, Benz |r El, Silberstein LE, Heslop H, Weitz |, Anastasi J, et al. Hematology: basic principles and practice. $7^{\text {th }}$ ed. Philadelphia: Elsevier; 2018.
3 Jaffe ES, Arber DA, Campo E, Harris NL, Quintanilla-Martinez L. Hematopathology. $2^{\text {nd }}$ ed. Philadelphia: Elsevier; 2016.

4 Niederhuber JE, Armitage JO, Doroshow JH, Kastan MB, Tepper JE. Abeloff's Clinical Oncology. $5^{\text {th }}$ ed. Philadelphia: Elsevier; 2013.

5 Ong E, Barraco F, Nighoghossian N, Praire A, Desestret V, Derex L, et al. 
Cerebrovascular events as presenting manifestations of myeloproliferative neoplasm. Rev Neurol (Paris). 2006;172(11):703-8

6 Arboix A, Jiménez C, Massons J, Parra O, Besses C. Hematological disorders: a commonly unrecognized cause of acute stroke. Expert Rev Hematol. 2016;9(9):891-901.

7 Bucaretchi F, De Capitani EM, Fernandes CB, Santos TM, Zamilute IA Hyslop S. Fatal ischemic stroke following Tityus serrulatus scorpion sting in a patient with essential thrombocythemia. Clin Toxicol (Phila) 2016;54(9):867-70.

8 Kato $Y$, Hayashi T, Sehara Y, Deguchi I, Fukuoka T, Maruyama H, et al. Ischemic stroke with essential thrombocythemia: a case series. J Stroke Cerebrovasc Dis. 2015;24(4):890-3.

9 Kitchens CS, Konkle BA, Kessler CM. Consultative hemostasis and thrombosis. $3^{\text {rd }}$ ed. Philadelphia: Elsevier; 2013. 